\title{
Preliminary Findings about the Implementation of Common Core State Standards Based on the May 2014 Field Tests of the American Teacher Panel and the American School Leader Panel
}

Julia H. Kaufman, Brian M. Stecher, and Laura S. Hamilton

RAND Education

WR-1057-BMGF

September 2014

This document has not been formally reviewed, edited, or cleared for public release. It may not be cited, quoted, reproduced or transmitted without the permission of the RAND Corporation. RAND's publications do not necessarily reflect the opinions of its research clients and sponsors. RAND ${ }^{\circledR}$ is a registered trademark. 
For more information on this publication, visit www.rand.org/pubs/working_papers/WR1057.html

Published by the RAND Corporation, Santa Monica, Calif.

(C) Copyright 2016 RAND Corporation

RAND $^{\star}$ is a registered trademark

\section{Limited Print and Electronic Distribution Rights}

This document and trademark(s) contained herein are protected by law. This representation of RAND intellectual property is provided for noncommercial use only. Unauthorized posting of this publication online is prohibited. Permission is given to duplicate this document for personal use only, as long as it is unaltered and complete. Permission is required from RAND to reproduce, or reuse in another form, any of its research documents for commercial use. For information on reprint and linking permissions, please visit www.rand.org/pubs/permissions.html.

The RAND Corporation is a research organization that develops solutions to public policy challenges to help make communities throughout the world safer and more secure, healthier and more prosperous. RAND is nonprofit, nonpartisan, and committed to the public interest.

RAND's publications do not necessarily reflect the opinions of its research clients and sponsors.

Support RAND

Make a tax-deductible charitable contribution at

www.rand.org/giving/contribute

www.rand.org 


\section{Introduction}

The American Teacher Panel (ATP) and the American School Leader Panel (ASLP) are resources that researchers, policymakers, and professional organizations can use to monitor over time the attitudes and behaviors of US teachers and school leaders ${ }^{1}$ in response to large-scale policy changes. There are many sources of information that provide popular opinions on education, but there are few that portray the perspectives of professional educators in ways that can be generalized beyond a small sample of participants. There are fewer still that allow us to track the evolving opinions and practices of teachers and principals over time. The ATP and ASLP address this gap: members will be drawn from a nationally representative sample of 2,300 schools (the principal and two teachers from each school); panelists will respond to four or more online surveys each year; and they will participate in the panels throughout their careers.

One national policy change of growing importance is the implementation of the Common Core State Standards (CCSS). The standards, developed over a period of years by the National Governors' Association, the Council of Chief State School Officers, and other organizations, set rigorous expectations for what students should know and be able to do in English language arts (ELA) and mathematics. As of 2014, over 40 states had adopted the CCSS or variations of them. Yet, the standards have become the subject of much political controversy, and a few states are considering rescinding their adoption or have done so already. Given the heightened rhetoric surrounding the standards, it is useful to know what teacher and principals think about them and how they are being implemented. This document presents illustrative findings from a field test of the panels, conducted in May 2014, focusing on perceptions and practices related to the CCSS.

When fully recruited, the ATP and ASLP surveys will yield highly accurate estimates of teacher and principal responses at the national level. The field test that produced the current results was conducted on a much smaller sample: 241 teachers and 153 principals (76\% of the teachers completed the survey, as did $60 \%$ of the principals). The field test sample lacked power to detect statistical significance in most cases, but the full ATP and ASLP panels will support more refined comparisons. We present these preliminary findings to illustrate the usefulness of the panels to answer policy questions. In addition to covering other topics, we will revisit questions about the CCSS in future surveys. Most of the findings reflect the responses of educators in schools that were embedding the CCSS, or standards directly adapted from CCSS, in instruction during the 2013-14 school year (based on teacher and principal reports). For ease of presentation, we refer to those 123 teachers and 70 principals as being "in CCSS schools." The findings have been weighted to produce national estimates. Unless otherwise noted, the findings all refer to teachers and principals in CCSS schools. In this report, we focus on findings related to principals' and teachers' opinions about the CCSS, their knowledge of standards, their expectations regarding changes needed to support the CCSS, the availability of appropriate instructional resources, and the use of selected instructional practices.

\section{Educators' Opinions about the CCSS}

The implementation of the CCSS is highly controversial. Some politicians, parents, and educators have criticized the CCSS (and other policies related to the CCSS), whereas others have expressed support for them.

\section{Large majorities of teachers and principals in CCSS schools believe the standards support student learning}

Teachers responded to a number of statements about the effects of standards on student learning and instruction. Their opinions about the potential effects of the CCSS on student outcomes were largely positive, suggesting that the standards will increase student learning and college and career readiness (see Figure 4).

Most teachers also indicated that the CCSS support cross-grade curriculum alignment. 
${ }^{1}$ At the present time, all members of the ASLP are principals; in the future, we may also include other school administrators. 


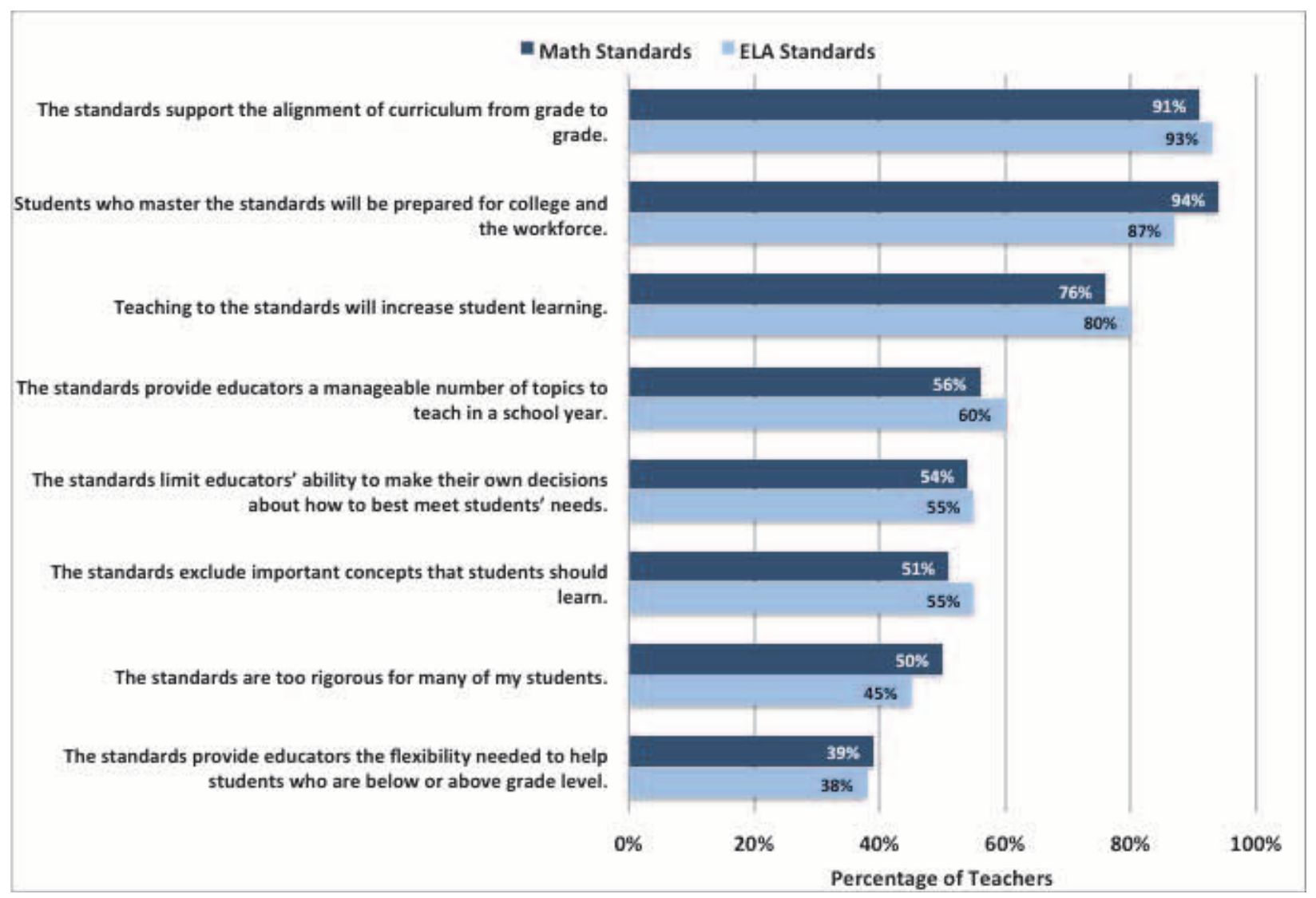

Figure 4. Teachers' Agreement with Statements about the CCSS

\section{Substantial numbers of teachers reported that the CCSS are too rigorous, inflexible, and cover too many topics.}

Teachers did express concerns about certain aspect of the standards. For example, a little over half thought the standards excluded important concepts that students should learn. If the CCSS are to be implemented successfully, these concerns will have to be addressed through education, support, or modifications.

Principals' responses were very similar to those of teachers, although a bit more positive about the CCSS. For example, only about one-quarter of principals agreed that ELA standards were too rigorous for many of their students ( 26 percent) or that mathematics standards were too rigorous for many of their students ( 28 percent).

\section{Knowledge of Standards}

One of the features of the CCSS in ELA and mathematics is that they also embody explicit expectations for teachers of other subjects. For example, social studies and science teachers are expected to help students master some ELA standards by embedding activities such as analysis of nonfiction texts in their lessons.

Science teachers are supposed to foster attainment of the mathematics standards by embedding relevant mathematics learning in their instruction. The preliminary findings show that teachers and principals in CCSS schools understand that the ELA and mathematics standards affect other subjects. That means, of course, that the provision of training and supports for implementing the CCSS will need to include teachers of these other subjects in addition to mathematics and ELA teachers. 
Most teachers and principals in CCSS schools know that they are expected to embed mathematics and ELA standards in other subjects

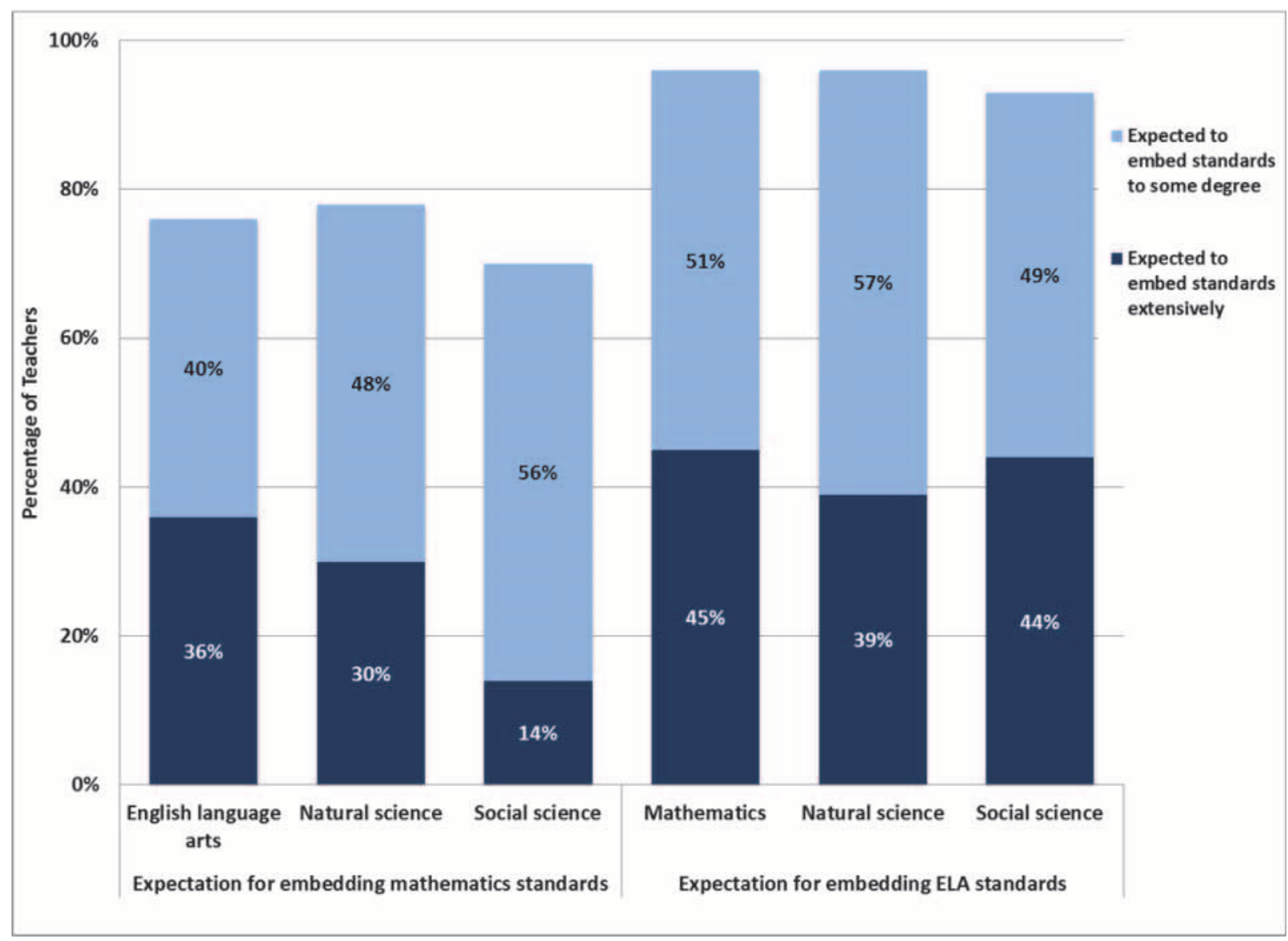

Figure 1. Teachers' Reports of District Expectations for Embedding Mathematics and ELA Standard in Other Subjects

For example, 78 percent of natural science teachers (general science, biology, chemistry, physics) in CCSS schools indicated that they were expected to embed mathematics standards in their instruction "to some degree" or "extensively" (see Figure 1). The expectations regarding the application of the ELA standards in other subject were even higher. For example, 44 percent of social science teachers in CCSS schools were expected to embed ELA standards "extensively" and another 49 percent "to some degree."

\section{Many teachers and principals in CCSS schools have only a general understanding of the standards}

The CCSS embody a number of changes to curriculum content and instructional emphases, and it is reasonable to assume that teachers will require some time to become fully familiar with them. Figure 2 shows that both mathematics and ELA teachers using the CCSS are developing familiarity with the standards but are not yet experts. More than one third have at best a general understanding of the standards. 


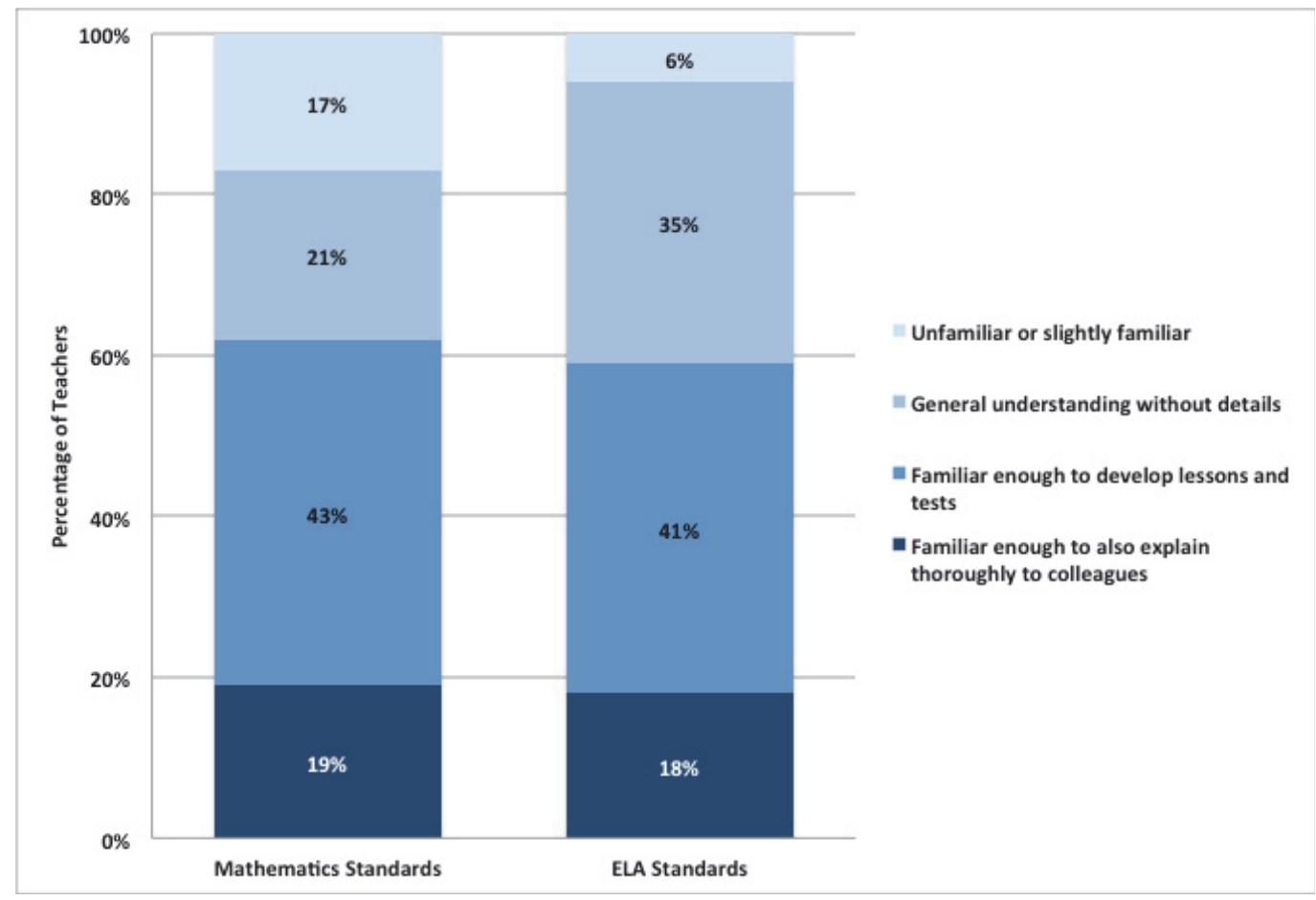

Figure 2. Teachers' Reports of Their Familiarity with Mathematics and ELA Standards

Similarly, about one-quarter of principals say they are familiar enough with CCSS standards to "discuss them and support teachers' use of them," i.e., to be strong instructional leaders with respect to promoting standards implementation (see Figure 3).

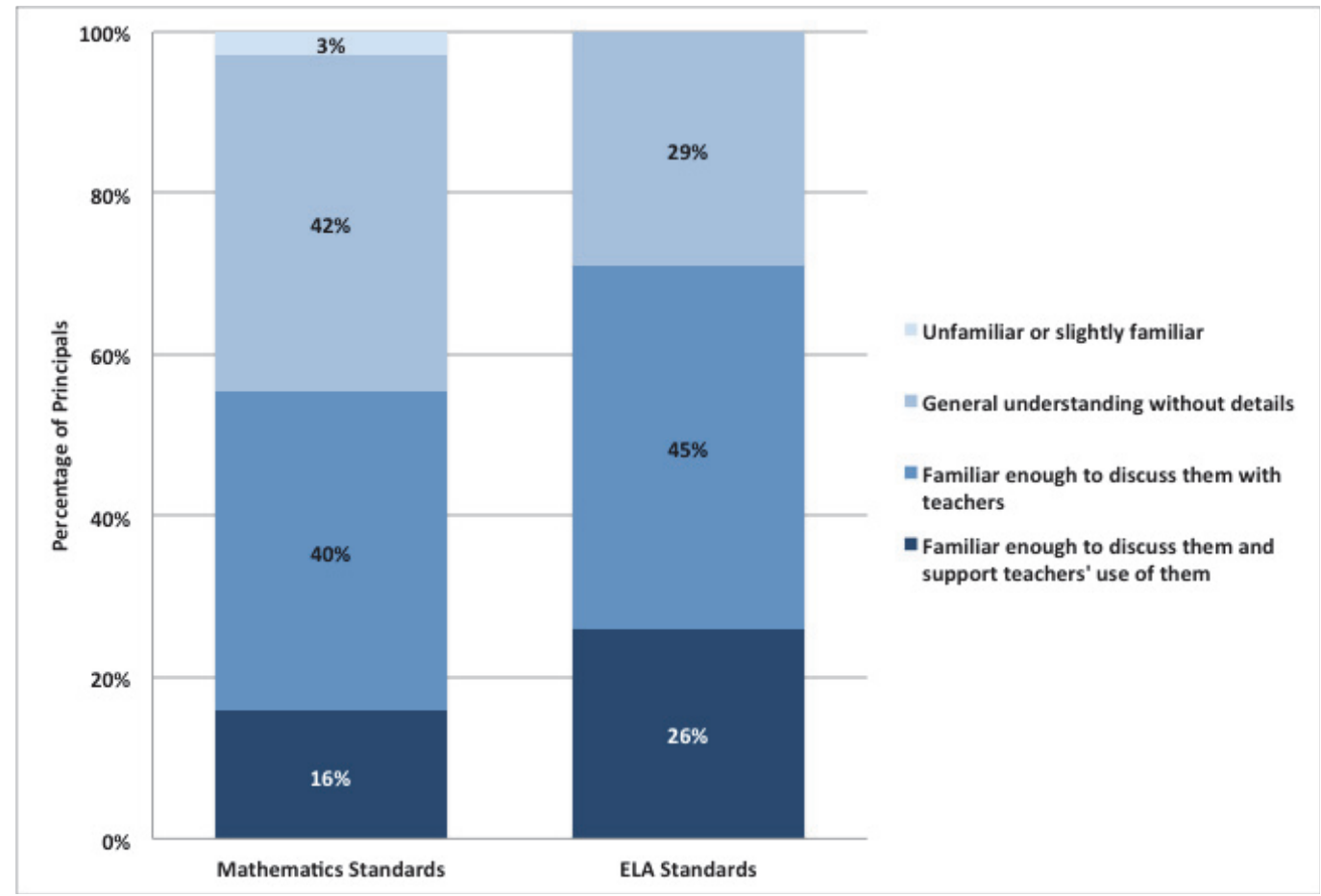

Figure 3. Principals' Reports of Their Familiarity with Mathematics and ELA Standards 


\section{Messages about Changes in Instruction}

It is important to understand the messages being communicated through the system about the degree of instructional change required to implement the new standards, because these messages can influence teachers' instructional decisions, from planning lessons to seeking support and assistance.

\section{Most teachers in CCSS schools have been told that the standards require changes to their instruction}

Almost half of the teachers received clear messages that the mathematics standards require some changes to their instruction, and over one-third received the message that the CCSS require major changes to instruction (see Figure 5, left panel). Consistent with this finding, principals reported sending strong messages to teachers in CCSS schools that changes are required, with close to one-half of principals indicating that major changes were needed in instruction (see Figure 5, right panel). The discrepancy between principals and teachers may reflect differences in their perception of the strength of the messages principals are sending.

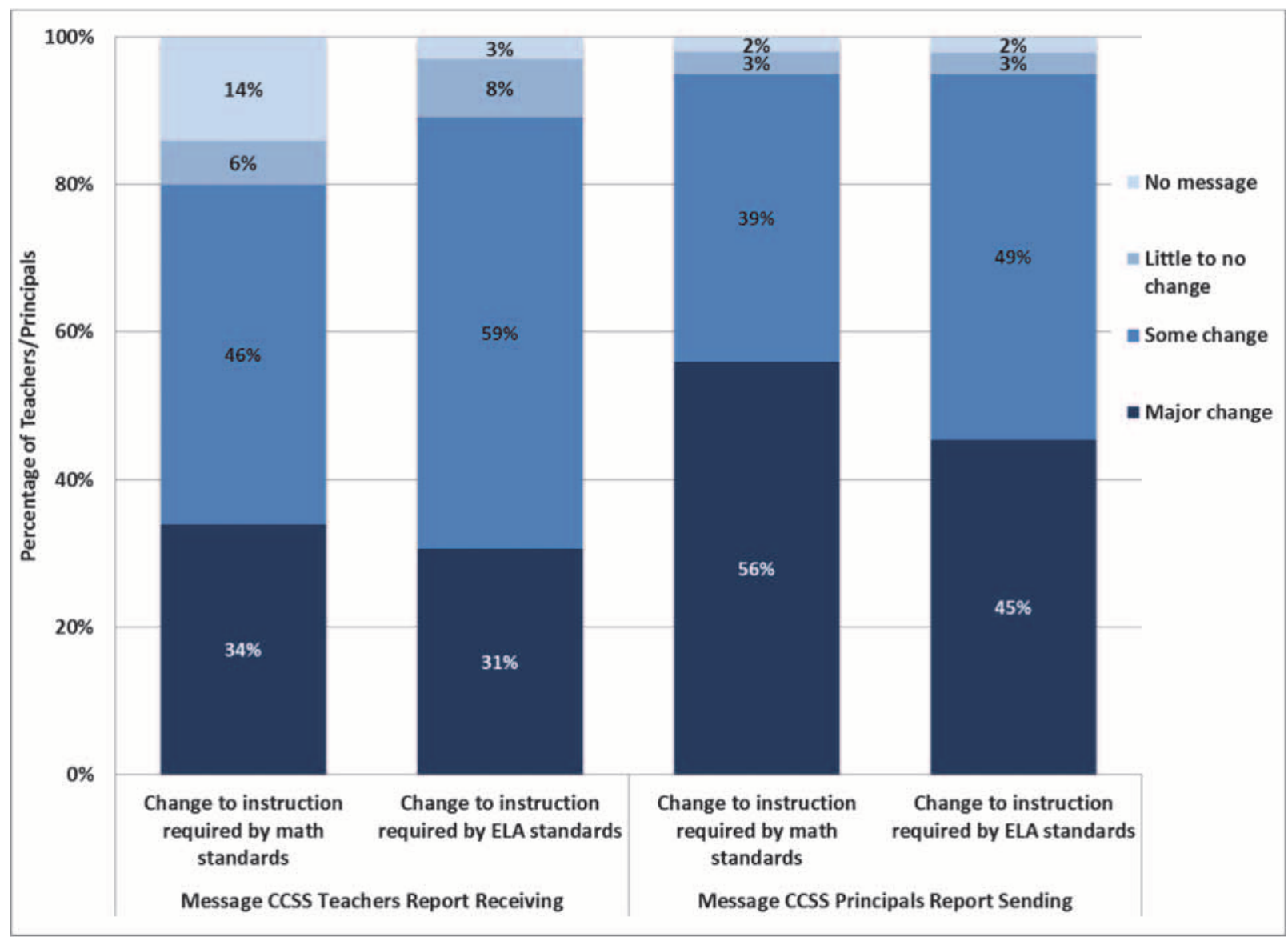

Figure 5. Principals' and Teachers' Reports of the Messages They Send and Receive Regarding the Instructional Changes Required by the CCSS

\section{Instructional Resources}

Teachers and principals both agree that new standards will require some changes to instruction, and it is important to know if the conditions exist to support such changes. Two key conditions are having instructional resources aligned to the new standards and receiving adequate training and support to change 
their practices. Teachers reported that existing instructional resources, including textbooks, state tests and district benchmark assessments, may not be adequately aligned with the CCSS. This deficiency might be expected when standards are newly implemented, but one would expect the situation to improve over time.

\section{Principals reported that existing instructional resources are not yet fully aligned with the CCSS}

Most principals and teachers using the CCSS agreed that their materials and assessments are not yet fully aligned to the CCSS, both in ELA and mathematics. As illustrated in Figure 6, approximately 25-30 percent of principals reported full alignment of their instructional materials and assessments.

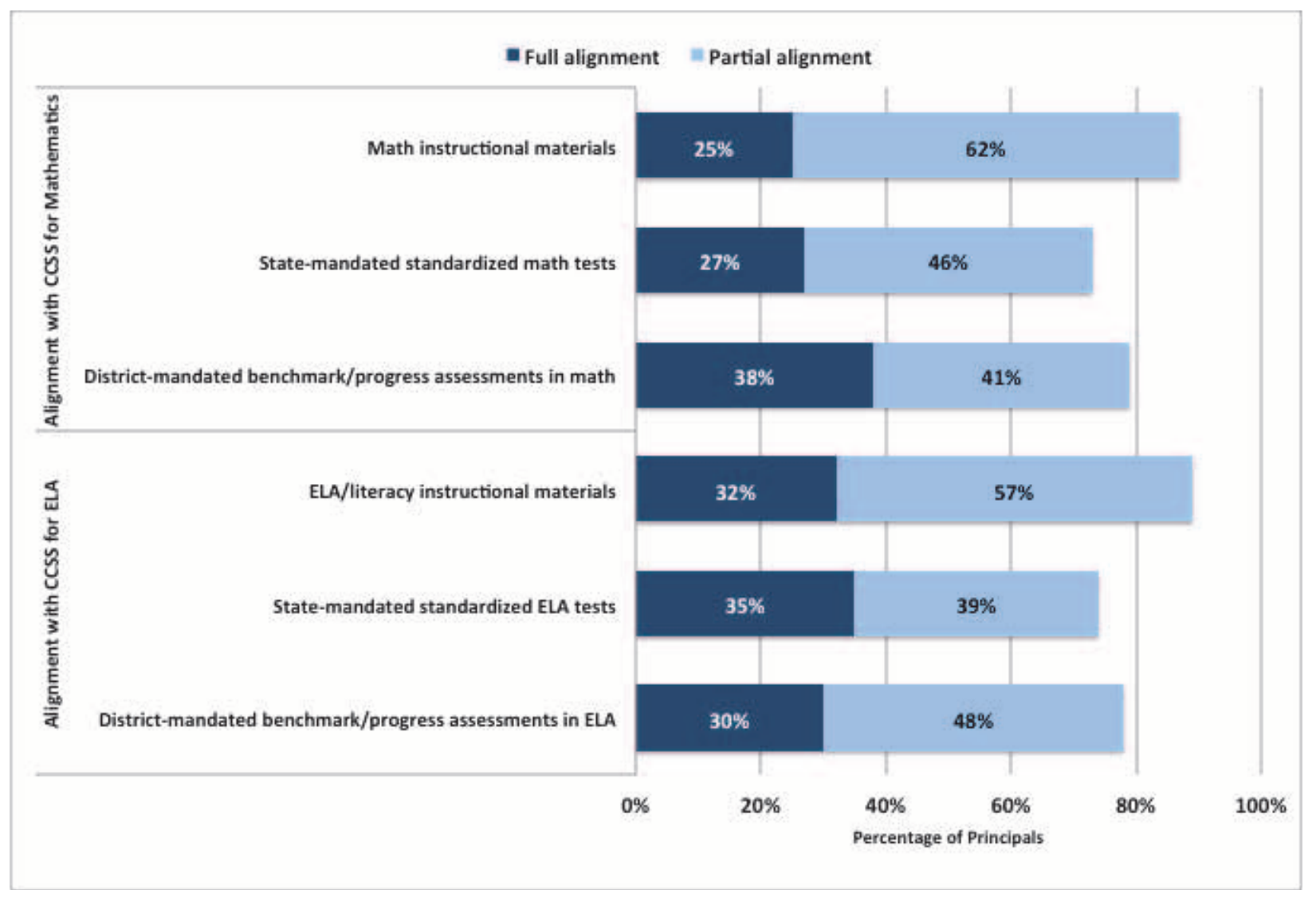

Figure 6. Principals' Reports of the Alignment of Instructional Resources with the CCSS

\section{Principals reported that teachers need CCSS-aligned instructional resources in greater quality and quantity}

To best help students meet the CCSS, teachers need access to a wide range of instructional resources aligned with the standards, including curriculum materials, lesson plans, instructional strategies and both formative and summative assessments. The majority of teachers reported at least some access to the curricula, lesson plans, ideas for instructional strategies, and assessments they need to help students meet standards. Principals' reports were similar. A high percentage of principals reported that their teachers needed many type of instructional resources in greater quantity or quality (see Figure 7). For example, over 90 percent reported that their teachers needed formative assessments that were aligned to standards in ELA and in mathematics. 


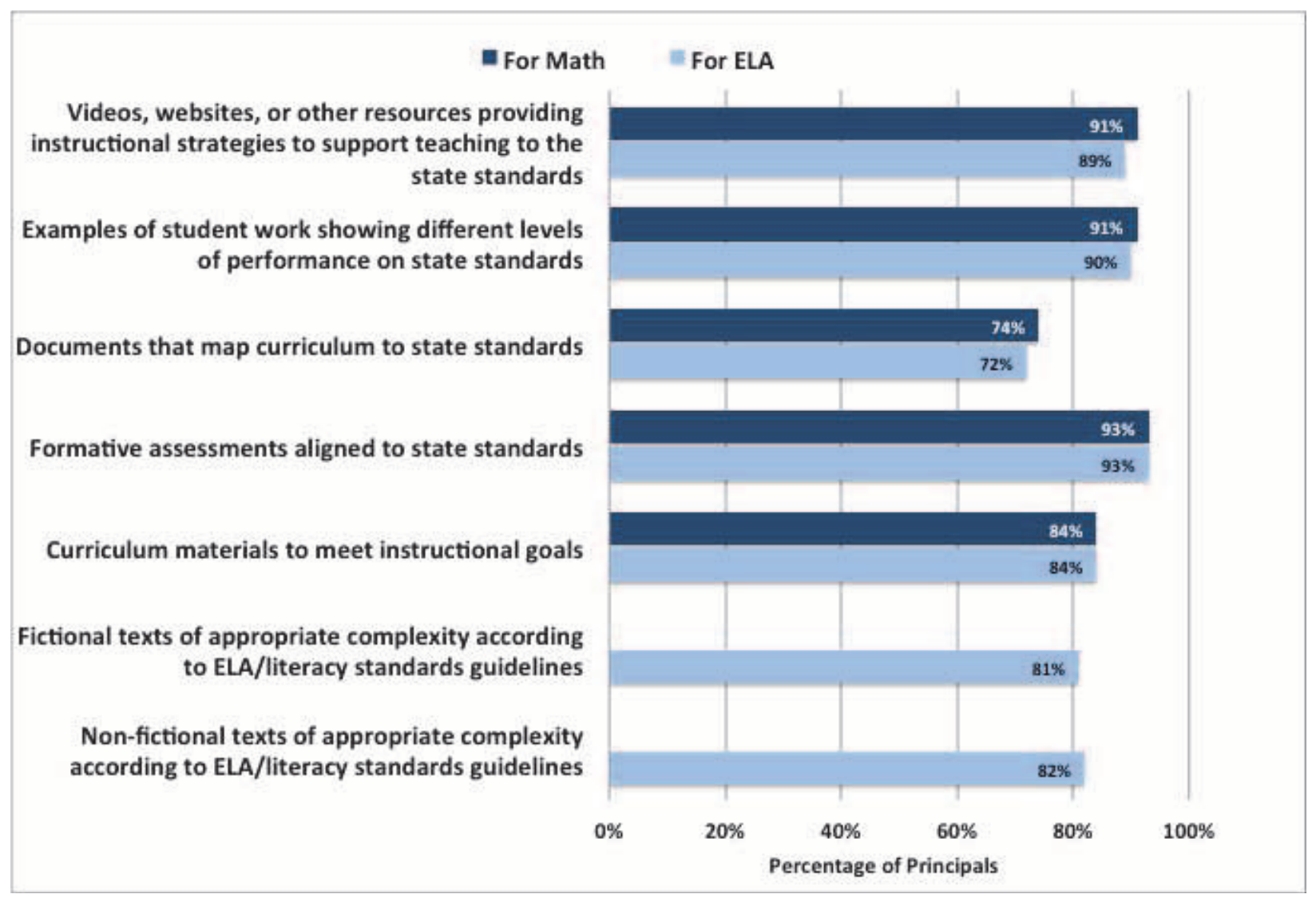

Figure 7. Principals' Reports of the Need for Instructional Resources to Help Student Meet the CCSS

\section{Instructional Practices}

The CCSS are not intended to tell teachers how to teach. Instead, teachers and schools determine the curriculum and lessons that best address the CCSS and how to differentiate for individual student needs. That said, the CCSS prescribe content and goals that could change what teachers do in their classrooms. For example, the CCSS for mathematics expect students to apply mathematics and statistics to everyday problems and to investigate patterns and relationships, and the CCSS for English language arts expect all students to practice with complex texts and engage in a diverse range of speaking and writing activities.

\section{Teachers in CCSS schools engage in key instructional practices more than teachers in non-CCSS schools}

Figures 8 and 9 show responses from teachers in CCSS and non-CCSS schools to questions about their students' engagement in practices that are consistent with the emphases of the CCSS (listed as items in each figure). The results suggest that teachers in CCSS schools engaged their students in these activities more frequently than teachers in non-CCSS schools. 


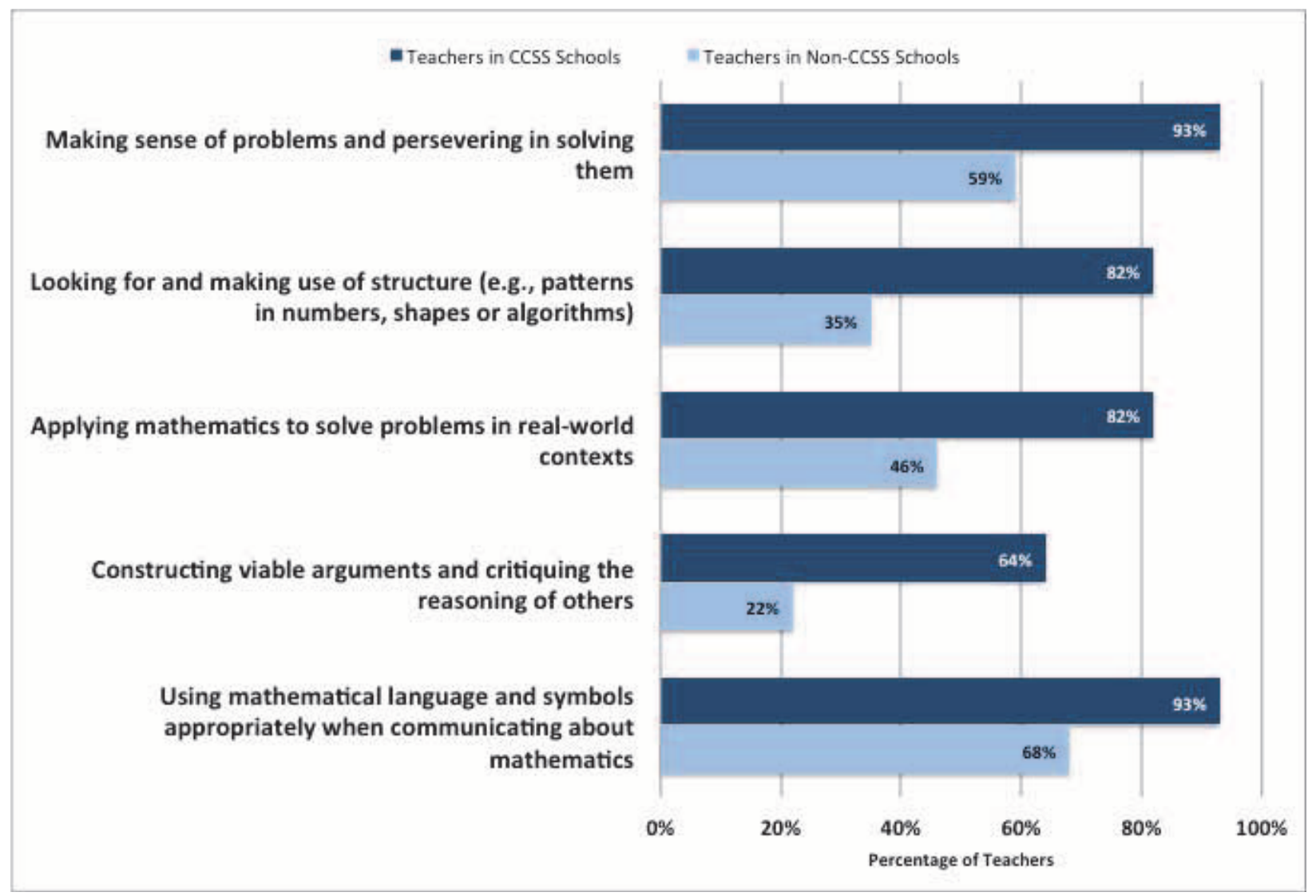

Figure 8. Teachers' Reports of Daily or Weekly Student Engagement in Specific Mathematics Practices 


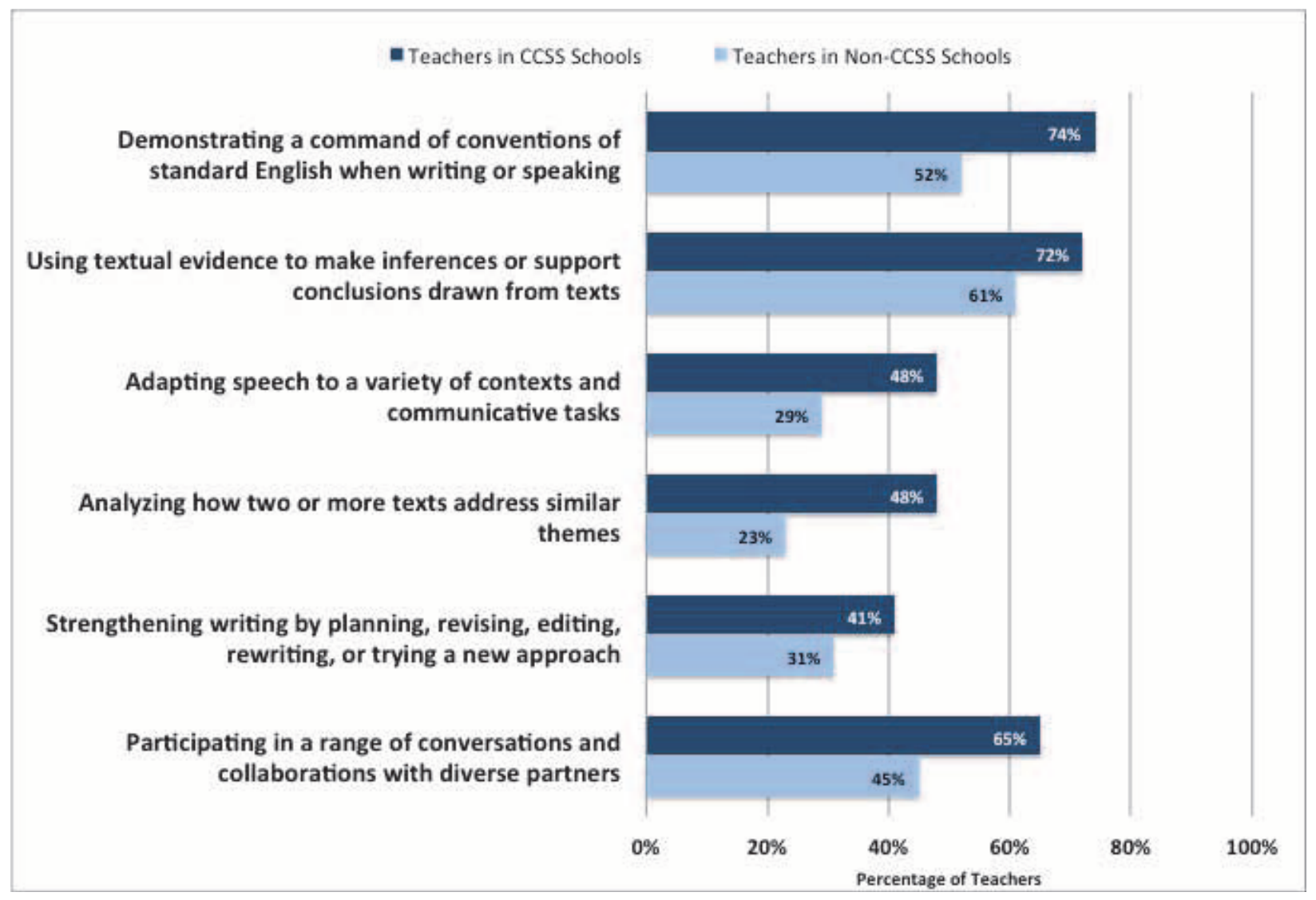

Figure 9. Teachers' Reports of Daily or Weekly Student Engagement in Specific ELA Practices

\section{Conclusions}

Results from the field test of the ATP and ASLP suggest that many teachers see potential for the CCSS to improve teaching and learning, but also identify some areas for concern.

- Most teachers implementing the CCSS seemed to understand the standards general terms, but many teachers and principals lacked adequate familiarity with their specific content.

- The majority of teachers believe that the CCSS will boost student success. Yet, many raised concerns that the standards are too rigorous, inflexible, and cover too many topics.

- Existing resources were not fully aligned with CCSS standards, and principals and teachers expressed needs for a variety of new resources, including resources to help judge student performance.

- Teachers in CCSS schools reported adopting practices that are consistent with the CCSS.

In our next report we will provide more information about some of these topics, as well as probe further into teachers' use of student performance data and teachers' access to and satisfaction with professional development to help them implement the CCSS. Future surveys, to be carried out in 2015 and subsequent years, will track responses over time to see how the CCSS implementation is progressing and identify implementation challenges principals and teachers are facing. These findings will provide a significant tool to help policymakers assess whether further efforts are needed to address these challenges. 